\title{
Immune inflammation indicators and implication for immune modulation strategies in advanced hepatocellular carcinoma patients receiving sorafenib
}

\author{
Andrea Casadei Gardini ${ }^{1}$, Emanuela Scarpi ${ }^{2}$, Luca Faloppi $i^{3,4}$, Mario Scartozzi ${ }^{4}$, \\ Nicola Silvestris ${ }^{5}$, Daniele Santini ${ }^{6}$, Giorgio de Stefano ${ }^{7}$, Giorgia Marisi ${ }^{8}$, Francesca \\ V. Negri ${ }^{9}$, Francesco Giuseppe Foschi ${ }^{10}$, Martina Valgiusti ${ }^{1}$, Giorgio Ercolani ${ }^{11,12}$, \\ Giovanni Luca Frassineti ${ }^{1}$ \\ ${ }^{1}$ Department of Medical Oncology, Istituto Scientifico Romagnolo per lo Studio e Cura dei Tumori (IRST) IRCCS, Meldola, \\ Italy \\ ${ }^{2}$ Unit of Biostatistics and Clinical Trials, IRST IRCCS, Meldola, Italy \\ ${ }^{3}$ Department of Medical Oncology, Ospedale Generale Provinciale di Macerata ASUR Marche AV3, Macerata, Italy \\ ${ }^{4}$ Department of Medical Oncology, University Hospital Cagliari, Cagliari, Italy \\ ${ }^{5}$ Medical Oncology Unit, Cancer Institute "Giovanni Paolo II", Bari, Italy \\ ${ }^{6}$ Medical Oncology Department, University Campus Bio-Medico, Via Álvaro del Portillo, Rome, Italy \\ ${ }^{7}$ Infectious Diseases and Interventional Ultrasound Unit, D. Cotugno Hospital, Naples, Italy \\ ${ }^{8}$ Biosciences Laboratory, IRST IRCCS, Meldola, Italy \\ ${ }^{9}$ Medical Oncology Unit, University Hospital, Parma, Italy \\ ${ }^{10}$ DPT Internal Medicine, Faenza Hospital, Faenza, AUSL Romagna, Forli, Italy \\ ${ }^{11}$ Department of General Surgery, Morgagni-Pierantoni Hospiatal, AUSL Romagna, Forli, Italy \\ ${ }^{12}$ Department of Medical and Surgical Sciences, University of Bologna, Bologna, Italy \\ Correspondence to: Andrea Casadei Gardini, email: andrea.casadei@irst.emr.it \\ Keywords: systemic immune-inflammation index, inflammation, biomarker, hepatocellular carcinoma, neutrophil-to-lymphocyte \\ ratio \\ Received: June 21, $2016 \quad$ Accepted: August 15, $2016 \quad$ Published: August 24, 2016
}

\section{ABSTRACT}

We evalueted a systemic immune-inflammation index (SII), neutrophil-tolymphocyte ratio (NLR) and platelet-lymphocyte ratio (PLR) with the aim to explored their prognostic value in patients with advanced hepatocellular carcinoma (HCC) treated with sorafenib. 56 advanced HCC patients receiving sorafenib were available for our analysis. Lymphocyte, neutrophil and platelet were measured before beginning of treatment and after one month. Patient with SII $\geq \mathbf{3 6 0}$ showed lower median PFS (2.6 vs. 3.9 months, $P<0.026)$ and $0 S(5.6$ vs. 13.9 months, $P=0.027$ ) with respect to patients with SII $<360$.

NLR $\geq 3$ had a lower median PFS ( 2.6 vs. 3.3 months, $P<0.049$ ) but not OS (5.6 vs. 13.9 months, $P=0.062$ ) than those with $N L R<3$. After adjusting for clinical covariates SII and NLR remained an independent prognostic factor for OS. The SII and NLR represent potential prognostic indicator in patients with advanced HCC treated with sorafenib.

\section{INTRODUCTION}

Hepatocellular carcinoma (HCC) represents the most common primary liver cancer with an increasing incidence [1].
The introduction of Sorafenib, currently representing the standard of care of advanced HCC, changed the clinical landscape even if a large proportion of patients show a limited efficacy with respect to toxic effects $[2,3$, $4,5,6,7]$. Until now predictive biomarkers of sorafenib 
efficacy or resistance have yet to be identified $[8,9,10$, $11,12,13]$.

Systemic inflammatory responses have been shown to reflect the promotion of angiogenesis, DNA damage and tumor invasion through up-regulation of cytokines [14]. Previous research revealed that lymphocytes play a crucial role in tumor defense by inducing cytotoxic cell death and inhibiting tumor cell proliferation and migration [15]. In consideration of these factors, several inflammation and immune-based prognostic scores, such as lymphocyte count, neutrophil-lymphocyte ratio (NLR), and systemic immune-inflammation index (SII), have been developed to predict survival and recurrence in cancers, including HCC $[16,17]$.

Cancer immunotherapy has made huge progress in the last few years. In particular, recent studies focalize the role of immune system in HCC. In fact, the unique immune response in the liver favors tolerance, which can represent a genuine challenge for conventional immunotherapy in patients with HCC [18].
Herein, we evaluated the potential role of SII, NLR and PLR as predictors of outcome in HCC patients treated with sorafenib.

\section{RESULTS}

\section{Patient characteristics}

56 patients diagnosed with HCC were consecutively treated with sorafenib. The patients caracteristics and clinical outcome show in Table 1.

\section{SII, NLR PLR and clinical outcome}

SII $\geq 360$ at baseline was associated with a median PFS of 2.6 months (95\% CI 2.0-2.9) compared to 3.9 months (95\% CI 2.8-6.2) for patients with SII $<360(P=$ .026) (HR 2.01, 95\%CI 1.07-3.75, $p=0.029$ ) (Figure 1a). $\mathrm{SII} \geq 360$ was associated with a median OS of 5.6 months (95\% CI 3.2-10.4) compared to 13.9 months (95\% CI 5.7-

Table 1: Univariate analysis of progression-free survival (PFS) and overall survival (OS)

\begin{tabular}{|c|c|c|c|c|c|c|}
\hline PFS & No. patients (\%) & No. events & Median PFS (95\% CI) & $P$ & HR $(95 \%$ CI $)$ & $P$ \\
\hline Overall & $56(100)$ & 46 & $2.8(2.6-3.9)$ & - & - & - \\
\hline $\begin{array}{l}\text { Age, years (continuous } \\
\text { variable) }\end{array}$ & - & - & - & - & $0.99(0.96-1.01)$ & 0.286 \\
\hline \multicolumn{7}{|l|}{ Gender } \\
\hline Male & $47(83.9)$ & 39 & $2.6(2.2-2.9)$ & & 1.00 & \\
\hline Female & $9(16.1)$ & 7 & $8.5(5.2-18.8)$ & 0.018 & $0.37(0.16-0.87)$ & 0.022 \\
\hline \multicolumn{7}{|l|}{ Etiology } \\
\hline Other & $25(44.6)$ & 19 & $2.9(1.4-6.0)$ & & 1.00 & \\
\hline Viral & $31(55.4)$ & 27 & $2.8(2.2-5.2)$ & 0.686 & $1.13(0.62-2.07)$ & 0.687 \\
\hline \multicolumn{7}{|l|}{ ECOG PS } \\
\hline 0 & $31(55.4)$ & 26 & $3.9(2.5-8.2)$ & & 1.00 & \\
\hline$\geq 1$ & $25(44.6)$ & 20 & $2.6(1.8-2.9)$ & 0.170 & $1.53(0.83-2.81)$ & 0.175 \\
\hline \multicolumn{7}{|l|}{ BCLC stage } \\
\hline B & $13(23.2)$ & 10 & $6.0(1.4-18.8)$ & & 1.00 & \\
\hline $\mathrm{C}$ & $43(76.8)$ & 36 & $2.7(2.3-3.3)$ & 0.060 & $2.01(0.96-4.20)$ & 0.065 \\
\hline \multicolumn{7}{|l|}{ Alpha-fetoprotein: } \\
\hline$<400$ & $32(59.3)$ & 24 & $2.7(2.0-3.9)$ & & 1.00 & \\
\hline$\geq 400$ & $22(40.7)$ & 20 & $3.7(2.3-10.8)$ & 0.123 & $0.59(0.30-1.17)$ & 0.128 \\
\hline \multicolumn{7}{|l|}{ MELD score } \\
\hline$\leq 10$ & $44(78.6)$ & 37 & $2.8(2.6-5.2)$ & & 1.00 & \\
\hline$>10$ & $12(21.4)$ & 9 & $2.6(0.9-3.7)$ & 0.832 & $1.09(0.50-2.36)$ & 0.833 \\
\hline \multicolumn{7}{|l|}{ Extrahepatic spread } \\
\hline Yes & 16 & 14 & $2.6(1.8-3.9)$ & & 1.00 & \\
\hline No & 40 & 32 & $3.3(2.6-6.0)$ & 0.110 & $0.59(0.31-1.14)$ & 0.116 \\
\hline
\end{tabular}

(Continued) 


\begin{tabular}{|c|c|c|c|c|c|c|}
\hline OS & No. patients (\%) & No. events & Median OS (95\% CI) & $\boldsymbol{P}$ & HR (95\% CI) & $\boldsymbol{P}$ \\
\hline Overall & $56(100)$ & 39 & $6.9(5.2-14.6)$ & - & - & - \\
\hline $\begin{array}{l}\text { Age, years } \\
\text { (continuous variable) }\end{array}$ & - & - & - & - & $0.98(0.96-1.00)$ & 0.107 \\
\hline \multicolumn{7}{|l|}{ Gender } \\
\hline Male & 47 (83.9) & 32 & $6.7(3.7-13.9)$ & & 1.00 & \\
\hline Female & $9(16.1)$ & 7 & $19.0(5.7-23.0)$ & 0.221 & $0.60(0.26-1.38)$ & 0.226 \\
\hline \multicolumn{7}{|l|}{ Etiology } \\
\hline Other & $25(44.6)$ & 15 & $6.8(3.7-14.6)$ & & 1.00 & \\
\hline Viral & $31(55.4)$ & 24 & $6.9(3.9-15.6)$ & 0.619 & $1.18(0.61-2.30)$ & 0.620 \\
\hline \multicolumn{7}{|l|}{ ECOG PS } \\
\hline 0 & $31(55.4)$ & 24 & $13.9(3.7-15.6)$ & & 1.00 & \\
\hline$\geq 1$ & $25(44.6)$ & 15 & $6.7(3.2-22.8)$ & 0.794 & $0.91(0.47-1.79)$ & 0.794 \\
\hline \multicolumn{7}{|l|}{ BCLC stage } \\
\hline B & $13(23.2)$ & 8 & $15.8(1.4-24.0)$ & & 1.00 & \\
\hline $\mathrm{C}$ & $43(76.8)$ & 31 & $6.7(3.9-13.9)$ & 0.092 & $1.96(0.88-4.36)$ & 0.098 \\
\hline \multicolumn{7}{|l|}{ Alpha-fetoprotein } \\
\hline$<400$ & $32(59.3)$ & 19 & $6.7(4.5-22.8)$ & & 1.00 & \\
\hline$\geq 400$ & $22(40.7)$ & 18 & $11.2(3.2-15.8)$ & 0.762 & $1.11(0.57-2.13)$ & 0.761 \\
\hline \multicolumn{7}{|l|}{ MELD score } \\
\hline$\leq 10$ & $44(78.6)$ & 31 & $11.2(5.2-15.6)$ & & 1.00 & \\
\hline$>10$ & $12(21.4)$ & 8 & $6.7(0.9-34.2)$ & 0.696 & $1.17(0.53-2.59)$ & 0.697 \\
\hline \multicolumn{7}{|l|}{ Extrahepatic spread } \\
\hline Yes & 16 & 13 & $5.2(3.1-14.6)$ & & 1.00 & \\
\hline No & 40 & 26 & $10.4(5.7-15.6)$ & 0.257 & $0.68(0.34-1.33)$ & 0.260 \\
\hline
\end{tabular}

22.8) for patients with SII $<360$ ( $P=.024)$ (HR 2.13, $95 \%$ CI 1.09-4.17, $p=0.027$ ) (Figure 1b).

SII $\geq 360$ at 1 months was associated with a median PFS of 2.6 months (95\% CI 1.8-3.3) compared to 3.9 months (95\% CI 2.8-6.2) for patients with SII $<360$ $(P=.024)($ HR $2.00,95 \%$ CI $1.08-3.70, p=0.027)$. SII $\geq 360$ was associated with a median OS of 5.7 months (95\% CI 3.1-13.9) compared to 11.2 months (95\% CI 6.8-15.6) for patients with $\mathrm{SII}<360(P=.087)$ (HR 1.76, $95 \%$ CI 0.91-3.38, $p=0.091)$. SII $<360$ showed a higher percentage of response at the first sorafenib re-evaluation than those SII $\geq 360$ ( $24 \% v s .0 \%$, respectively) ( $P=$ 0.039) (Table 2).

To evaluate SII modifications during the course of treatment. We considered PFS and OS after stratifying patients into 2 groups according to SII levels at baseline and after second blood sample. The first group included patients with high $(<360)$-high $(\geq 360)$ levels of SII, while the second included those with high $(\geq 360)$-low $(<360)$, low $(<360)$-low $(<360)$ SII. Patients in the first group had a median PFS of 2.5 months compared to 3.9 months for those in the second group (HR 1.77, 95\% CI 0.93-3.36, $\mathrm{p}=0.08$ ) (Figure 1c). OS was 13.9 months in the first group and 5.2 months in the second group (HR 2.07, 95\% CI $1.03-4.13, \mathrm{p}=0.040$ ) (Figure 1d).

NLR $\geq 3$ was associated with a median PFS of 2.6 months (95\% CI 1.7-3.7) compared to 3.3 months $(95 \%$ CI 2.6-6.2) for patients with NLR $<3(P=.049)$ (HR $1.84,95 \%$ CI $0.99-3.41, p=0.053$ ) (Figure 1e). NLR $\geq 3$ was associated with a median OS of 5.6 months $(95 \%$ CI 2.2-10.4) compared to 13.9 months (95\% CI 5.2-20.9) for patients with NLR $<3(P=.058)$ (HR 1.87, 95\%CI 0.97$3.60, p=0.062$ ) (Figure 1f).

PLR $\geq 15.0$ was associated with a median PFS of 2.6 months (95\% CI 2.0-5.2) compared to 2.9 months (95\% CI 2.6-8.2) for patients with PLR $<0.15(P=.430)$ (HR 1.30, 95\%CI 0.68-2.49, $p=0.433$ ) (Figure 1g). PLR $<15.0$ was associated with a median OS of 6.9 months (95\% CI 5.6-13.9) compared to 14.6 months (95\% CI 2.2$10.0)$ for patients with PLR $\geq 15.0(P=.815)$ (HR 1.09, 95\%CI 0.53-2.26, $p=0.815$ ) (Figure $1 \mathrm{~h}$ ).

NLR and PLR modifications during the course of treatment show in Table 3.

The counts for neutrophils, lymphocytes and platelets alone without the ratio and clinical outcome show in Table 4. 
After adjusting for clinical covariates (age, gender, etiology, BCLC stage, ECOG performance status), SII and NLR remained an independent prognostic factor for OS (SII: HR=2.99, 95\% CI 1.34-6.68, $\mathrm{p}=0.007$; NLR: $\mathrm{HR}=2.36,95 \%$ CI $1.07-5.18, \mathrm{p}=0.033)$ but not for PFS $(\mathrm{HR}=1.73,95 \%$ CI 0.91-3.29, $\mathrm{p}=0.096$; NLR: HR=1.81, $95 \%$ CI $0.92-3.58, \mathrm{p}=0.088)$.

\section{DISCUSSION}

In the present study, SII and NLR was show to be an indipendent predictor of OS for patients with HCC treated with sorafenib. Our results suggest that the SII could be a more objective marker that reflects the balance between host inflammatory and immune response status than indexes such as the PLR and NLR. In addition, our data have shown that a high SII basal and a month is associated with a worse prognosis respect other patients.

In neoplastic process, inflammatory cells are powerful tumor promoters; they produce an attractive environment for tumor growth, facilitating genomic instability and promoting angiogenesis [19]. Tumors are often infiltrated by various numbers of lymphocytes, macrophages and mast cells. It has been suggested that lymphocytes play central roles in host antitumor immune responses. Mouse models have shown that lymphocytes may control cancer outcome [20].

As an integrated indicator based on peripheral lymphocyte, neutrophil, and platelet counts, the predictive value of SII for cancer outcomes might be due to the function of these three types of cells. Lymphocytes and platelets have been proven to promote tumor development. In addition, recent evidence indicates that neutrophils enhance cancer cell invasion, proliferation, and metastasis and assist cancer cells with evading immune surveillance.

Several studies have shown that platelets induces circulating tumor cell epithelial-mesenchymal transition and promotes extravasation to metastatic sites $[21,22]$. Neutrophils promote adhesion and seeding of distant organ sites through the secretion of circulating growth factors such as vascular endothelial growth factor (VEGF) and proteases $[23,24]$. Lymphocytes play a crucial role in tumor defense by inducing cytotoxic cell death and inhibiting tumor cell proliferation and migration, thereby
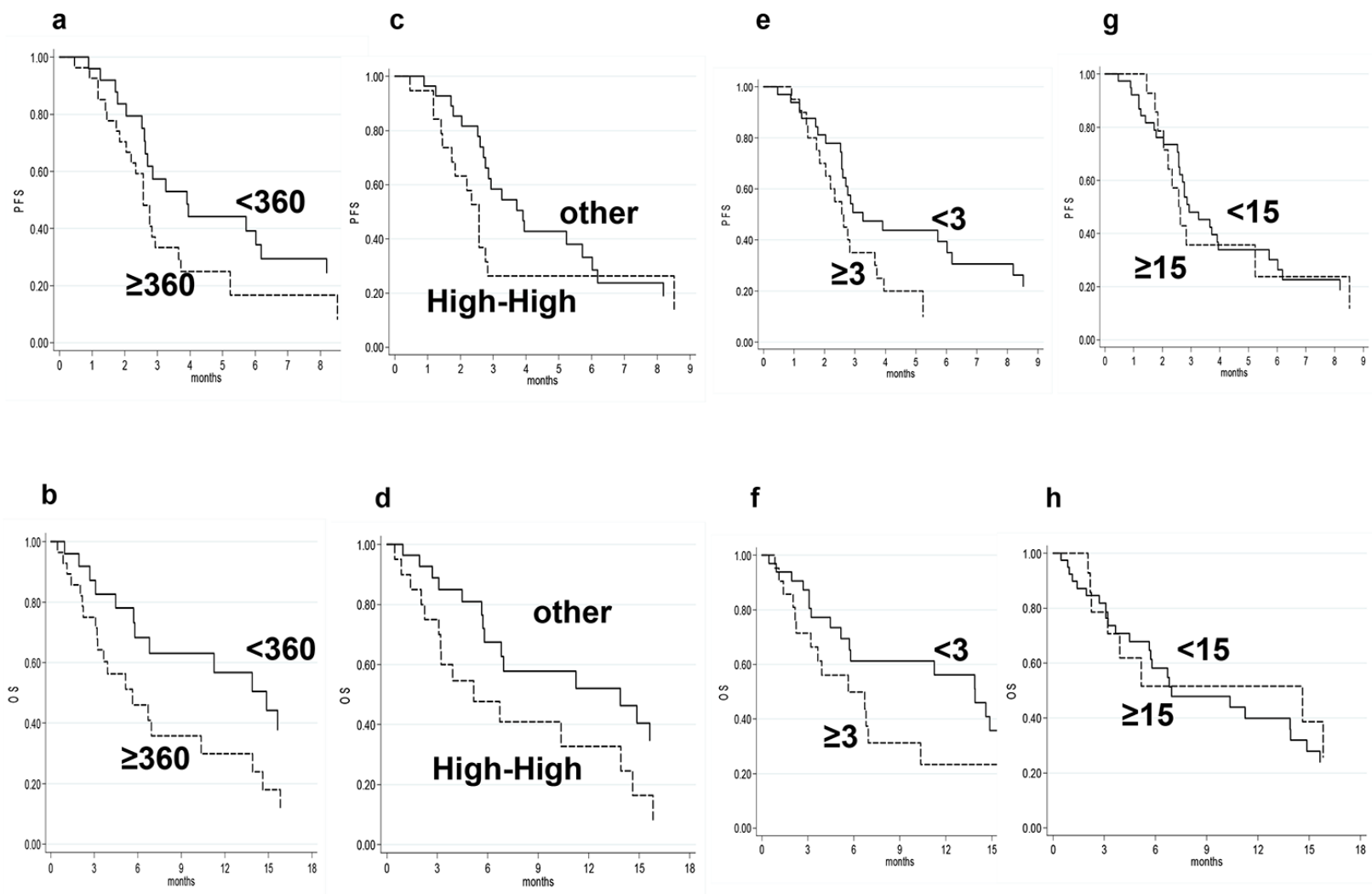

$\mathbf{h}$

Figure 1: a. Progression-free survival (PFS) in relation to SII at baseline; b. Overall survival (OS) in relation to SII at baseline; c. Progression-free survival (PFS) in relation to SII modifications during the course of treatment; d. Overall survival (OS) in relation to SII modifications during the course of treatment; e. Progression-free survival (PFS) in relation to NLR; f. Overall survival (OS) in relation to NLR; g. Progression-free survival (PFS) in relation to PLR; h. Overall survival (OS) in relation to PLR. 
Table 2: Association between SII, NLR and PLR and ORR

\begin{tabular}{|c|c|c|c|c|c|c|c|c|c|}
\hline & \multicolumn{3}{|c|}{ SII (baseline) } & \multicolumn{3}{|c|}{ NLR (baseline) } & \multicolumn{3}{|c|}{ PLR (baseline) } \\
\hline & $<360$ & $\geq 360$ & & $<3$ & $\geq 3$ & & $<15.0$ & $\geq 15.0$ & \\
\hline & No. $(\%)$ & No. $(\%)$ & $\boldsymbol{P}$ & No. $(\%)$ & No. $(\%)$ & $\boldsymbol{P}$ & No. (\%) & No. $(\%)$ & $\boldsymbol{P}$ \\
\hline \multicolumn{10}{|l|}{ ORR } \\
\hline $\mathrm{CR}+\mathrm{PR}$ & $5(23.8)$ & 0 & & $5(19.2)$ & 0 & & $5(15.6)$ & 0 & \\
\hline $\mathrm{SD}+\mathrm{PD}$ & $16(76.2)$ & $24(100)$ & 0.039 & $21(80.8)$ & $19(100)$ & 0.063 & $27(84.4)$ & $13(100)$ & 0.301 \\
\hline
\end{tabular}

SII, systemic immune-inflammation index; NLR, neutrophil-to.lymphocyte ratio; PLR, platelet-to-lymphocyte ratio; ORR, objective response rate; $\mathrm{CR}$, complete response; $\mathrm{PR}$, partial response; $\mathrm{SD}$, stable disease; $\mathrm{PD}$, progressive disease

Table 3: NLR and PLR modifications during the course of treatment

\begin{tabular}{|c|c|c|c|c|c|c|c|}
\hline & \multirow{2}{*}{ N. pts } & \multicolumn{3}{|c|}{ PFS } & \multicolumn{3}{|c|}{ OS } \\
\hline & & N. events & HR $(95 \%$ CI) & p & N. events & HR $(95 \%$ CI) & p \\
\hline NLR & 48 & 41 & $\begin{array}{c}1.08(0.98- \\
1.20)\end{array}$ & 0.129 & 35 & $1.15(1.03-1.27)$ & 0.010 \\
\hline PLR & 49 & 42 & $\begin{array}{c}0.98(0.94- \\
1.02)\end{array}$ & 0.348 & 36 & $1.01(0.97-1.05)$ & 0.710 \\
\hline
\end{tabular}

Table 4: The counts for neutrophils, lymphocytes and platelets alone without the ratio and clinical outcome

\begin{tabular}{|c|c|c|c|c|c|c|}
\hline & N.pts & N. events & Median PFS (95\% CI) & p & HR (95\% CI) & p \\
\hline Neutrofili: & & & & & $1.000(1.000-1.000)$ & 0.181 \\
\hline$<\mathrm{UNL}$ & 8 & 7 & $3.9(2.5-11.2)$ & & $0.77(0.34-1.75)$ & 0.533 \\
\hline$<>\mathrm{UNL}$ & 43 & 35 & $2.8(2.2-3.9)$ & & 1.00 & \\
\hline >UNL & 5 & 4 & $2.3(1.2-\mathrm{nr})$ & 0.516 & $1.59(0.56-4.58)$ & 0.386 \\
\hline Linfociti: & & & & & $1.000(1.000-1.000)$ & 0.317 \\
\hline$\leq \mathrm{UNL}$ & 13 & 13 & $2.6(1.8-3.9)$ & & 1.00 & \\
\hline$>$ UNL & 43 & 33 & $2.9(2.5-6.0)$ & 0.287 & $0.70(0.37-1.35)$ & 0.291 \\
\hline Piastrine: & & & & & $1.000(0.996-1.003)$ & 0.811 \\
\hline \multirow[t]{2}{*}{$\leq \mathrm{UNL}$} & 21 & 17 & $3.9(2.0-8.2)$ & & 1.00 & \\
\hline & N. pts & N. events & Median OS (95\% CI) & $\mathbf{p}$ & HR $(95 \%$ CI) & p \\
\hline Neutrofili: & & & & & $1.000(1.000-1.000)$ & 0.199 \\
\hline$<\mathrm{UNL}$ & 8 & 5 & $13.1(4.5-n r)$ & & $0.57(0.22-1.47)$ & 0.244 \\
\hline$<>\mathrm{UNL}$ & 43 & 31 & $6.9(3.7-14.6)$ & & 1.00 & \\
\hline$>\mathrm{UNL}$ & 5 & 3 & $6.7(2.0-\mathrm{nr})$ & 0.419 & $1.34(0.40-4.52)$ & 0.639 \\
\hline Linfociti: & & & & & $1.000(0.999-1.000)$ & 0.307 \\
\hline$\leq \mathrm{UNL}$ & 13 & 11 & $5.2(2.2-19.0)$ & & 1.00 & \\
\hline$>$ UNL & 43 & 28 & $11.2(5.7-15.6)$ & 0.107 & $0.56(0.27-1.15)$ & 0.112 \\
\hline Piastrine: & & & & & $0.999(0.995-1.002)$ & 0.431 \\
\hline$\leq \mathrm{UNL}$ & 21 & 15 & $6.8(3.1-20.9)$ & & 1.00 & \\
\hline$>\mathrm{UNL}$ & 35 & 24 & $6.9(5.2-14.9)$ & 0.655 & $1.16(0.60-2.25)$ & 0.656 \\
\hline
\end{tabular}


dictating the host's immune response to malignancy [25]. Thus, inflammation induces changes in the cancer microenvironment changes that favor cancer progression.

Ipilimumab is a monoclonal antibody that works to activate the immune system by targeting CTLA-4, a protein receptor that downregulates the immune system. Recent works on melanoma have shown thatb derived neutrophil-to-lymphocyte ratio may be associated with response to these drugs [26, 27]. For this reason, our work highlights the possible benefit of a subset of patients with advanced hepatocellular carcinoma to treatment with ipilimumab. In conclusion the low cost, easy determination, and reproducibility of a full blood count make SII and NLR a promising tool for assessing HCC prognosis in future clinical practice.

\section{PATIENTS AND METHODS}

\section{Patient population}

This retrospective study was conducted on 56 HCC patients consecutively treated at our institute (Istituto Scientifico Romagnolo per lo Studio e la Cura dei Tumori) from 2012 to 2015.

We enrolled only patients receiving oral treatment with either $400 \mathrm{mg}$ of sorafenib (consisting of 2200 $\mathrm{mg}$ tablets) twice daily. Treatment with sorafenib was continued until disease progression, unacceptable toxicity or death occurred. Disease progression was assessed using Modified Response Evaluation Criteria in Solid Tumors (mRECIST).

\section{Statistical analysis}

The aim of this analysis was to examine the association between baseline SII, NLR and PLR levels and Progression-Free Survival (PFS) and Overall Survival (OS) in patients with HCC treated with sorafenib.

Information on neutrophil, lymphocyte and platelet counts from hematologic blood tests carried out at baseline (the day before the start of treatment) and one month was collected. Complete blood counts have been carried out with XE-2100 (Sysmex, Kobe, Japan).

The SII was calculated as platelet count $\times$ neutrophil count/lymphocyte count, NLR was obtained by dividing the absolute neutrophil count by the absolute lymphocyte count, and the PLR was calculated by as the ratio of the absolute platelet count to the absolute lymphocyte count.

Association between categorical variables was assessed using the Fisher's exact test, when appropriate.

PFS was defined as the time interval between the day of start of treatment and the day of documented disease progression, last follow-up visit if there was no progression or the day of death. OS was defined as the time interval between the day of start of treatment until the day of death or last follow-up visit. PFS and OS were estimated by the Kaplan-Meier method and curves were compared by the log-rank test. Unadjusted and adjusted hazard ratios (HRs) by baseline characteristics (age, gender, etiology, ECOG performance status) were calculated using the Cox proportional hazards model.

We also conducted landmark analyses to reduce possible confounding by time on treatment by assessing the impact of change in SII; NLR and PLR at 1 month landmark time on survival outcomes. X-tile 3.6.1 software (Yale University, New Haven, CT) was used to determine the cutoff value for baseline levels of each II. SII $\geq 360$, NLR $\geq 3$ and PLR $\geq 15$ were considered as elevated levels.

All $p$ values were based on two-sided testing and statistical analyses were performed using SAS statistical software version 9.4 (SAS Inc., Cary, NC, USA).

\section{ACKNOWLEDGMENTS}

The authors would like to thank Ursula Elbling for editing the manuscript.

\section{CONFLICTS OF INTEREST}

All the other authors have no conflict of interest to declare. The manuscript has not been published previously, and is not under consideration, in whole or in part, for publication elsewhere.

\section{Author contributions}

ACG conceived and designed the study. ACG, ES collected and assembled the study data. ACG, LF, MS, NS, GFF, GLF, MV: analyzed and interpreted the data. All authors contributed to the drafting and revision of the manuscript and approved the final version

\section{Ethical approval}

The study protocol was reviewed and approved by the local Ethics Committee (CEIIAV: comitato etico IRST IRCCS AVR). Study number IRST B041 protocol nu,ber 5482/v.1 intern code: L3P1192. All patients signed their written informed consent.

\section{REFERENCES}

1. Casadei Gardini A, Marisi G, Scarpi E, Scartozzi M, Faloppi L, Silvestris N, Masi G, Vivaldi C, Brunetti O, Tamberi S, Foschi FG, Tamburini E, Tenti E, et al. Effects of metformin on clinical outcome in diabetic patients with advanced HCC receiving sorafenib. Expert Opin Pharmacother. 2015; 16:2719-2725. doi: 10.1517/146565 66.2015.1102887.

2. Casadei Gardini A, Scarpi E, Marisi G, Foschi FG, Donati G, Giampalma E, Faloppi L, Scartozzi M, Silvestris N, Bisulli M, Corbelli J, Gardini A, La Barba G, et al. Early 
onset of hypertension and serum electrolyte changes as potential predictive factors of activity in advanced HCC patients treated with sorafenib: results from a retrospective analysis of the HCC-AVR group. Oncotarget. 2016; 7:15243-15251. doi: 10.18632/oncotarget.7444.

3. Cheng AL, Kang YK, Chen Z, Tsao CJ, Qin S, Kim JS, Luo R, Feng J, Ye S, Yang TS, Xu J, Sun Y, Liang H, et al. Efficacy and safety of sorafenib in patients in the AsiaPacific region with advanced hepatocellular carcinoma: a phase III randomised, double-blind, placebo-controlled trial. Lancet Oncol. 2009; 10:25-34. doi: 10.1016/ S1470-2045(08)70285-7.

4. Coffelt SB and de Visser KE. Cancer: Inflammation lights the way to metastasis. Nature. 2014; 507:48-49. doi: $10.1038 /$ nature 13062 .

5. Casadei Gardini A, Marisi G, Faloppi L, Scarpi E, Giuseppe Foschi F, Iavarone M, Lauletta G, Corbelli J, Valgiusti M, Facchetti F, Corte C, Maria Neri L, Tamberi S, et al. eNOS polymorphisms and clinical outcome in advanced HCC patients receiving sorafenib: final results of the ePHAS study. Oncotarget. 2016; 7:27988-27999. doi: 10.18632/ oncotarget.8569.

6. Faloppi L, Bianconi M, Memeo R, Casadei Gardini A, Giampieri R, Bittoni A, Andrikou K, Del Prete M, Cascinu S, Scartozzi M. Lactate Dehydrogenase in Hepatocellular Carcinoma: Something Old, Something New. Biomed Res Int. 2016; 2016:7196280. doi: 10.1155/2016/7196280.

7. Casadei Gardini A, Chiadini E, Faloppi L, Marisi G, Delmonte A, Scartozzi M, Loretelli C, Lucchesi A, Oboldi D, Dubini A, Frassineti GL, Ulivi P. Efficacy of sorafenib in BRAF-mutated non-small-cell lung cancer (NSCLC) and no response in synchronous BRAF wild type-hepatocellular carcinoma: a case report. BMC Cancer. 2016; 16:429. doi: 10.1186/s12885-016-2463-2.

8. Cools-Lartigue J, Spicer J, McDonald B, Gowing S, Chow S, Giannias B, Bourdeau F, Kubes P, Ferri L. Neutrophil extracellular traps sequester circulating tumor cells and promote metastasis. J Clin Invest. 2013. doi: 10.1172/ JCI67484.

9. Coussens LM, Werb Z. Inflammation and cancer. Nature. 2002; 420:860-867. doi:10.1038/nature01322.

10. De Giorgi U, Mego M, Scarpi E, Giuliano M, Giordano A, Reuben JM, Valero V, Ueno NT, Hortobagyi GN, Cristofanilli M. Relationship between lymphocytopenia and circulating tumor cells as prognostic factors for overall survival in metastatic breast cancer. Clin Breast Cancer. 2012; 12:264-269. doi: 10.1016/j.clbc.2012.04.004.

11. Faloppi L, Scartozzi M, Bianconi M, Svegliati Baroni G, Toniutto P, Giampieri R, Del Prete M, De Minicis S, Bitetto D, Loretelli C, D'Anzeo M, Benedetti A, Cascinu S. The role of $\mathrm{LDH}$ serum levels in predicting global outcome in HCC patients treated with sorafenib: implications for clinical management. BMC Cancer. 2014;14:110. doi: 10.1186/1471-2407-14-110.
12. Faloppi L, Scartozzi M, Maccaroni E, Di Pietro Paolo M, Berardi R, Del Prete M, Cascinu S. Evolving strategies for the treatment of hepatocellular carcinoma: from clinical-guided to molecularly-tailored therapeutic options. Cancer Treat Rev. 2011; 37:169-177. doi: 10.1016/j. ctrv.2010.08.001.

13. Ferrucci PF, Ascierto PA, Pigozzo J, Del Vecchio M, Maio M, Antonini Cappellini GC, Guidoboni M, Queirolo P, Savoia P, Mandala M, Simeone E, Valpione S, Altomonte $\mathrm{M}$, et al. Baseline neutrophils and derived neutrophilto-lymphocyte ratio: prognostic relevance in metastatic melanoma patients receiving ipilimumab. Ann Oncol. 2016; 27:732-738. doi: 10.1093/annonc/mdw016.

14. Ferrucci PF, Gandini S, Battaglia A, Alfieri S, Di Giacomo AM, Giannarelli D, Cappellini GC, De Galitiis F, Marchetti P, Amato G, Lazzeri A, Pala L, Cocorocchio E, et al. Baseline neutrophil-to-lymphocyte ratio is associated with outcome of ipilimumab-treated metastatic melanoma patients. Br J Cancer. 2015; 112:1904-1910. doi: 10.1038/ bjc.2015.180.

15. Hu B, Yang XR, Xu Y, Sun YF, Sun C, Guo W, Zhang X, Wang WM, Qiu SJ, Zhou J, Fan J. Systemic immuneinflammation index predicts prognosis of patients after curative resection for hepatocellular carcinoma. Clin Cancer Res. 2014; 20:6212-6222. doi: 10.1158/1078-0432. CCR-14-0442.

16. Kane RC, Farrell AT, Madabushi R, Booth B, Chattopadhyay S, Sridhara R, Justice R, Pazdur R. Sorafenib for the treatment of unresectable hepatocellular carcinoma. Oncologist. 2009;14:95-100. doi: 10.1634/ theoncologist.2008-0185.

17. Kobayashi N, Usui S, Kikuchi S, Goto Y, Sakai M, Onizuka $\mathrm{M}$, Sato Y. Preoperative lymphocyte count is an independent prognostic factor in node-negative non-small cell lung cancer. Lung Cancer. 2012; 75:223-227. doi: 10.1016/j. lungcan.2011.06.009.

18. Labelle M, Begum S, Hynes RO. Direct signaling between platelets and cancer cells induces an epithelial-mesenchymallike transition and promotes metastasis. Cancer Cell. 2011; 20:576-590. doi: 10.1016/j.ccr.2011.09.009.

19. Llovet JM, Pena CE, Lathia CD, Shan M, Meinhardt G, Bruix J, SHARP Investigators Study Group. Plasma biomarkers as predictors of outcome in patients with advanced hepatocellular carcinoma. Clin Cancer Res. 2012; 18: 2290-2300. doi: 10.1158/1078-0432. CCR-11-2175.

20. Llovet JM, Ricci S, Mazzaferro V, Hilgard P, Gane E, Blanc JF, de Oliveira AC, Santoro A, Raoul JL, Forner A, Schwartz M, Porta C, Zeuzem S, et al. Sorafenib in advanced hepatocellular carcinoma. N Engl J Med. 2008; 359:378-390. doi: 10.1056/NEJMoa0708857.

21. Mossanen JC, Tacke F. Role of lymphocytes in liver cancer. Oncoimmunology. 2013; 2:e26468. doi: 10.4161/ onci. 26468. 
22. Pages F, Galon J, Dieu-Nosjean MC, Tartour E, SautesFridman C, Fridman WH. Immune infiltration in human tumors: a prognostic factor that should not be ignored. Oncogene. 2010; 29:1093-1102. doi: 10.1038/onc.2009.416.

23. Prieto J, Melero I, Sangro B. Immunological landscape and immunotherapy of hepatocellular carcinoma. Nat Rev Gastroenterol Hepatol. 2015; 12:681-700. doi: 10.1038/ nrgastro.2015.173.

24. Rossi L, Santoni M, Crabb SJ, Scarpi E, Burattini L, Chau C, Bianchi E, Savini A, Burgio SL, Conti A, Conteduca V, Cascinu S, De Giorgi U. High neutrophil-to-lymphocyte ratio persistent during first-line chemotherapy predicts poor clinical outcome in patients with advanced urothelial cancer. Ann Surg Oncol. 2015; 22:1377-1384. doi: 10.1245/ s10434-014-4097-4.

25. Scartozzi M, Faloppi L, Svegliati Baroni G, Loretelli C, Piscaglia F, Iavarone M, Toniutto P, Fava G, De Minicis
S, Mandolesi A, Bianconi M, Giampieri R, Granito A, et al. VEGF and VEGFR genotyping in the prediction of clinical outcome for HCC patients receiving sorafenib: the ALICE-1 study. Int J Cancer. 2014; 135:1247-1256. doi: $10.1002 /$ ijc. 28772 .

26. Schumacher D, Strilic B, Sivaraj KK, Wettschureck N, Offermanns S. Platelet-derived nucleotides promote tumorcell transendothelial migration and metastasis via P2Y2 receptor. Cancer Cell. 2013; 24:130-137. doi: 10.1016/j. ccr.2013.05.008.

27. Shao YY, Hsu CH, Cheng AL. Predictive biomarkers of antiangiogenic therapy for advanced hepatocellular carcinoma: where are we? Liver Cancer. 2013; 2:93-107. doi: $10.1159 / 000343845$. 